\title{
Overexpression of Peptide-Encoding OsCEP6.1 Results in Pleiotropic Effects on Growth in Rice (O. sativa)
}

\author{
Zhipeng Sui ${ }^{1,2}$, Tianya Wang ${ }^{1,2}$, Hongjian $L^{1,2}$, Ming Zhang ${ }^{1,2}$, Yangyang $L i^{1,2}$, Ruibin $X u^{3}$, \\ Guofang Xing ${ }^{4}$, Zhongfu $\mathrm{Ni}^{1,2 *}$ and Mingming $\mathrm{Xin}^{1,2 *}$
}

${ }^{1}$ Key Laboratory of Crop Heterosis and Utilization (MOE) and State Key Laboratory for Agrobiotechnology, Beijing Key Laboratory of Crop Genetic Improvement, China Agricultural University, Beijing, China, ${ }^{2}$ National Center for Plant Gene Research-Beijing, Beijing, China, ${ }^{3}$ Qingdao Agricultural University, Qingdao, China, ${ }^{4}$ Shanxi Agricultural University, Taigu, China

\section{OPEN ACCESS}

Edited by:

Joshua L. Heazlewood,

The University of Melbourne, Australia

Reviewed by:

Michael Djordjevic,

Australian National University, Australia

Ana Fernandez,

Vlaams Instituut voor Biotechnologie,

Belgium

*Correspondence:

Zhongfu Ni

niz@cau.edu.cn;

Mingming Xin

mingmingxin@cau.edu.cn

Specialty section:

This article was submitted to

Plant Proteomics,

a section of the journal

Frontiers in Plant Science

Received: 18 October 2015

Accepted: 11 February 2016

Published: 02 March 2016

Citation:

Sui Z, Wang T, Li H, Zhang M, LiY, Xu R, Xing G, Ni Z and Xin M (2016) Overexpression of Peptide-Encoding

OSCEP6.1 Results in Pleiotropic Effects on Growth in Rice (O. sativa).

Front. Plant Sci. 7:228

doi: 10.3389/fpls.2016.00228
Plant peptide hormones play an important role in regulating plant developmental programs via cell-to-cell communication in a non-cell autonomous manner. To characterize the biological relevance of C-TERMINALLY ENCODED PEPTIDE (CEP) genes in rice, we performed a genome-wide search against public databases using a bioinformatics approach and identified six additional CEP members. Expression analysis revealed a spatial-temporal pattern of OsCEP6.1 gene in different tissues and at different developmental stages of panicle. Interestingly, the expression level of the OsCEP6.1 was also significantly up-regulated by exogenous cytokinin. Application of a chemically synthesized 15-amino acid OsCEP6.1 peptide showed that OsCEP6.1 had a negative role in regulating root and seedling growth, which was further confirmed by transgenic lines. Furthermore, the constitutive expression of OSCEP6.1 was sufficient to lead to panicle architecture and grain size variations. Scanning electron microscopy analysis revealed that the phenotypic variation of OSCEP6.1 overexpression lines resulted from decreased cell size but not reduced cell number. Moreover, starch accumulation was not significantly affected. Taken together, these data suggest that the OsCEP6.1 peptide might be involved in regulating the development of panicles and grains in rice.

Keywords: rice, signaling peptide, CEP, grain size, cell size

\section{INTRODUCTION}

Intercellular communication is a fundamental mechanism for coordinating the development of multicellular organisms. Plant peptide hormones have been recognized as an important signal mediating cell-to-cell communication in a non-cell autonomous manner and regulating many processes of biological relevance, including meristem maintenance, cell proliferation and root development (Katsir et al., 2011). Among the peptide families, the C-TERMINALLY ENCODED PEPTIDE (CEP) genes encode a mature post-translationally modified peptide of 15 -amino acids, excised from a precursor including an N-terminal secretion signal (NSS), a variable domain, one or more CEP domains and a short C-terminal extension (Ohyama et al., 2008). To date, more than $900 C E P$ genes have been identified across plant genomes. CEP genes are predominantly

Abbreviations: ZH17, Zhong Hua 17; CEP, C-TERMINALLY ENCODED PEPTIDE; DAP, days after pollination; SSII, STRACH SYNTHASE II. 
present in gymnosperm and angiosperm plants, but absent from the earliest diverging lineages of plants, indicating that their emergence coincided with the evolution of seed plants. A preliminary phylogenetic analysis of CEP genes divided them into two groups based on the homology of CEP domains (Delay et al., 2013; Roberts et al., 2013; Ogilvie et al., 2014). Although Arabidopsis CEP genes are mainly expressed in vasculature, a spatiotemporal expression pattern is still observed for most members (Roberts et al., 2013). Recent emerging evidences have demonstrated that CEPs are involved in the regulation of plant root/shoot growth, lateral root and root nodule development (Ohyama et al., 2008; Delay et al., 2013; Imin et al., 2013; Roberts et al., 2013; Tabata et al., 2014; Mohd-Radzman et al., 2015). For example, Arabidopsis treated with chemically synthesized CEP1 peptide or ectopically expressing of AtCEP1 exhibits repressed primary root growth and retarded lateral root elongation by reducing the cell number in the meristem zone and decreasing the cell size in the mature region (Ohyama et al., 2008). The ectopic expression of $M t C E P 1$ or exogenous application of the synthetic peptide reduces the number of emerged lateral roots; by contrast, simultaneous down-regulation of MtCEP1, 2, 5, and 11 dramatically increases lateral root numbers (Imin et al., 2013; Mohd-Radzman et al., 2015), whereas the AtCEP3 loss-of-function mutation promotes root development under high $\mathrm{NaCl}$ concentration and nitrogen-limiting condition (Delay et al., 2013). In addition, peptide application experiments or the constitutive expression of other six CEPs (AtCEP2, AtCEP3, AtCEP4, AtCEP5, AtCEP6, and AtCEP9) results in repressed root development (Ohyama et al., 2008; Delay et al., 2013; Roberts et al., 2013). However, the function of these peptides is significantly different in the control of above-ground traits, e.g., no significant changes are observed in AtCEP1 overexpression lines, such as leaf number, flowering time and fruit set, whereas reduced leaf number and delayed flowering time are found in AtCEP2 overexpression lines. Moreover, overexpression of AtCEP3 shows leaf epinasty, leaf etiolation and small leaves (Ohyama et al., 2008; Delay et al., 2013; Roberts et al., 2013). Furthermore, CEP family peptides can be induced by local nitrate starvation and act as an ascending $\mathrm{N}$-demand signal to the shoot to mediate up-regulation of nitrate transporter genes (Imin et al., 2013; Tabata et al., 2014; Mohd-Radzman et al., 2015). Peptide sequences always involve some posttranslational modifications, including tyrosine sulfation, proline hydroxylation and hydroxyproline arabinosylation, which are known to modulate the ability and specificity of peptides for target receptor proteins by affecting peptide conformation (Matsubayashi, 2011). The synthetic MtCEP1 domain 1 peptides D1:HyP4,11 (hydroxylation occurred at Pro4 and Pro11) and D1:HyP7,11 increase the nodule number, whereas D1:HyP4,11 and D1:HyP4,7,11 inhibit the lateral root development (MohdRadzman et al., 2015). However, Delay et al. (2013) reported that both CEP9.1 and CEP9.1 H (hydroxylation occurred at Pro4 and Pro11) reduced the length of the primary root in Arabidopsis, although the CEP9.1 $\mathrm{H}$ activity was higher than CEP9.1 (Delay et al., 2013). In addition, Kondo et al. (2006) reported that proline hydroxylation of CLV3 showed no difference in root growth inhibition compared with the peptide without modifications (Kondo et al., 2006).
Rice grain yield is a complex agronomic trait that is multiplicatively governed by three main components: number of panicles per plant, number of grains per panicle and grain weight (Xing and Zhang, 2010). Previous studies have reported that the MONOCULM1 mutant significantly decreased rice yield by negatively controlling tiller formation (Li et al., 2003). Whereas repression of the GRAIN NUMBER1 (Gn1a), encoding cytokinin oxidase/dehydrogenase, promotes cytokinin accumulation in rice inflorescence meristem and increases grain number (Ashikari et al., 2005). A number of genes involved in the regulation of grain width and length are map-based cloned, including GS3, GL3.1/qGL3, TGW6, GW2, qSW5/GW5, GS5, and GW8 (Fan et al., 2006; Song et al., 2007; Weng et al., 2008; Li et al., 2011; Qi et al., 2012; Wang et al., 2012; Ishimaru et al., 2013). Furthermore, the disruption of gene expression related to endosperm developmental processes leads to the failure of seed maturation and yield loss (Zhou et al., 2013). For example, the suppression of MADS29 expression promotes programmed cell death (PCD) of the nucellus and the nucellar projection in rice, resulting in shrunken seeds (Nayar et al., 2013); overexpression of OsFIE1 shortens the duration of the syncytial stage, causes precocious cellularization and ultimately leads to small seeds (Ishikawa et al., 2011; Folsom et al., 2014).

As a model system of monocots, 11 CEP genes have been identified in rice by a bioinformatics approach based on peptide sequence conservation (Delay et al., 2013; Roberts et al., 2013; Ogilvie et al., 2014). To date, no further investigation has been conducted to explore their biological importance. In this study, we performed a genome-wide search of CEP genes across the rice genome and identified another six CEP genes, overexpression of OsCEP6.1 caused a series of phenotypic variations compared with the control, including reduced root length, decreased tiller number and repressed plant height. More interestingly, overexpression of OsCEP6.1 resulted in small seeds via the reduction of cell size but not of cell number.

\section{MATERIALS AND METHODS}

\section{Plant Materials and Growth Conditions}

Chinese rice cultivar Zhong Hua 17 (ZH17) was used for the experiments in this study. $\mathrm{ZH} 17$ and transgenic rice seeds were sterilized with diluted $(1: 3, \mathrm{v} / \mathrm{v}) \mathrm{NaClO}$ for $15 \mathrm{~min}$ and rinsed with sterile water 5 times. Seed germination was placed in the dark at $28^{\circ} \mathrm{C}$ for $72 \mathrm{~h}$. The 6-day-old seedlings were transferred to nutrient solution containing $1.425 \mathrm{mM}$ $\mathrm{NH}_{4} \mathrm{NO}_{3}, 0.323 \mathrm{mM} \mathrm{NaH} \mathrm{PO}_{4}, 0.513 \mathrm{mM} \mathrm{K} \mathrm{SO}_{4}, 0.998 \mathrm{mM}$ $\mathrm{CaCl}_{2}, 1.643 \mathrm{mM} \mathrm{MgSO}_{4}, 0.168 \mathrm{mM} \mathrm{Na}_{2} \mathrm{SiO}_{3}, 0.125 \mathrm{mM} \mathrm{Fe}-$ EDTA, $0.019 \mathrm{mM} \mathrm{H}_{3} \mathrm{BO}_{3}, 0.009 \mathrm{mM} \mathrm{MnCl}_{2}, 0.155 \mathrm{mM} \mathrm{CuSO}_{4}$, $0.152 \mathrm{mM} \mathrm{ZnSO}_{4}$, and $0.075 \mathrm{mM} \mathrm{Na}_{2} \mathrm{MoO}_{4}, \mathrm{pH}$ 5.5. The hydroponic experiments were conducted with a 16-h-light $\left(30^{\circ} \mathrm{C}\right) / 8$-h-dark $\left(22^{\circ} \mathrm{C}\right)$ photoperiod, and the solution was refreshed every 3 days (Wang et al., 2009; Dai et al., 2012). Fully filled grains were used to measure grain length and width of five overexpression lines ( $\mathrm{Li}$ et al., 2004). Grain weight (calculated by 100 grains) was determined in triplicate, and converted to the 1000-grain weight (Wu et al., 2008; Mao et al., 2010).Statistically significant differences were detected using a two-sample $T$-test (SPSS ver 17.0, Chicago, USA) where appropriate. 


\section{Genome-Wide Identification, Chromosomal Location, and Phylogenetic Analysis of Rice CEP Genes}

Eleven rice CEPs have been predicted via homology BLAST against public databases (Delay et al., 2013; Ogilvie et al., 2014). Rice CEP domains and all Arabidopsis CEP domains were used as query sequences for protein BLAST against NCBI nonredundant reference proteins (http://blast.ncbi.nlm.nih.gov) and the Rice Genome Annotation Project (http://rice.plantbiology. msu.edu). Then, all the full-length CEP protein sequences were used to predict NSS by performing SignalP (http:// www.cbs.dtu.dk/services/SignalP) and SecretomeP (http://www. cbs.dtu.dk/services/SecretomeP-2.0/) interface software. The position of CEP genes on the rice genome was identified by the Genome Browser (http://rice.plantbiology.msu.edu). Phylogenetic analyses of rice CEP domains were conducted using the neighbor-joining algorithm in MEGA5 (Tamura et al., 2011) considering 1000 replications with bootstrap analyses. Rice CEP domain conservation was shown by WebLogo plots (http:// weblogo.berkeley.edu) (Crooks et al., 2004).

\section{Vector Construction and Rice Transformation}

For overexpression, the 321-bp CDS of OsCEP6.1 was amplified using the primer pair of OsCEP6.1-L and OsCEP6.1-R, and the resulting PCR product was cloned into the pCAMBIA1300-Ubi vector. The plasmid was co-precipitated with golden particles and introduced into Zhonghua17 (ZH17). At the T2 generation, two independent transgenic lines were used for further analysis.

\section{RNA Isolation and Real-Time Quantitative PCR}

The primary root and shoot of the 6-day-old seedlings; the leaf, palea, lemma and stamen at the rice heading stage; and four different length panicles were collected. The required tissues (primary root, shoot, leaf, palea, lemma, stamen, pistil, and panicles at four different developmental stages) were collected at the proper stages and frozen in liquid nitrogen. The total RNA was extracted using the Trizol RNA isolation protocol (Life Technologies, USA). The first strand of cDNA was synthesized from total RNA using the Superscript II RT Kit (Invitrogen, Carlsbad, CA, USA).

Real-time qPCR experiments were performed using SYBR Green PCR master mix (TaKaRa, Otsu, Japan) on CFX96 RealTime PCR Detection System (Bio-Rad Laboratories, Inc., USA). Specific primer pairs for the qRT-PCR analysis were listed in Table S1. PCR conditions consisted of an initial step at $95^{\circ} \mathrm{C}$ for $3 \mathrm{~min}$ followed by 40 cycles of $95^{\circ} \mathrm{C}$ for $15 \mathrm{~s}, 59^{\circ} \mathrm{C}$ for $15 \mathrm{~s}$, and $72^{\circ} \mathrm{C}$ for $30 \mathrm{~s}$. Ct values were determined using the CFX96 software with default settings. Differences between the Ct values of target gene and Actin1 were calculated as $\Delta \mathrm{Ct}=\mathrm{Ct}_{\text {targetgene }}{ }^{-}$ $\mathrm{Ct}_{\text {Actin } 1}$, and the relative expression levels of target genes were determined as $2^{-\Delta \mathrm{Ct}}$. The average values of $2^{-\Delta \mathrm{Ct}}$ were used to determine the difference in gene expression. Data were analyzed as described above.

\section{Exogenous Hormone Treatment and Synthetic CEP Treatment}

After the germination of rice seeds, the 6-day-old seedlings were transferred to nutrient solution with or without $10 \mu \mathrm{M}$ NAA (1-naphthalene acetic acid), 1, 3, 5, 10, and $20 \mu \mathrm{M}$ 6-BA (6-benzylaminopurine), $10 \mu \mathrm{M} \mathrm{GA}_{3}$ (gibberellic acid), $100 \mu \mathrm{M}$ ABA (abscisic acid), $1 \mu \mathrm{M}$ BR (Epibrassinolide), $100 \mu \mathrm{M}$ MeJA (methyljasmonate) and $50 \mu \mathrm{M}$ ACC (1-aminocyclo-propane-1carboxylic acid) (Lee et al., 1996; Cheng et al., 2007; Kurakawa et al., 2007; Tanaka et al., 2009; Yang et al., 2011), $6 \mathrm{~h}$ after hormone treatment, the roots were collected. Total RNA was extracted and analyzed by real-time RT-PCR. Moreover, the uniformly germinated seeds were transferred into the nutrient solution with or without synthetic CEP peptides in the cylindrical glass bottle (diameter $=4 \mathrm{~cm}$, height $=10 \mathrm{~cm}$ ) for phenotypic detection, the solution was refreshed every 3 days. Synthetic CEP peptides (DSRPTAPGNSPGIGN) without modifications were synthesized by SBS Genetech (Beijing, China), and the purity of the synthetic peptides was greater than $95 \%$, as assessed by reverse phase high-performance liquid chromatography (Figure S1). Data were analyzed as described above.

\section{Microscopic Observations}

The outer spikelet hull surfaces and the inner epidermal cells of the lemma were observed and imaged through scanning electron microscopy (TM-3000, Hitachi, Japan), The distance between the tubercles of outer surface $(n=200)$ and the cell length and width of inner epidermal cell $(n=250)$ were measured using ImageJ software (http://rsb.info.nih.gov/ij/). Data were analyzed as described above.

\section{Histological Analysis}

Spikelet hulls at heading stage and grains at 2, 5, and 8 days after pollination were fixed in FAA (50\% ethanol, 5\% glacial acetic acid and 5\% formaldehyde) for $24 \mathrm{~h}$, dehydrated in an ethanol series, and embedded in Paraplast (Sigma). Tissue sections ( $8 \mathrm{~mm}$ thick) were cut, mounted and stained with safranin $\mathrm{T}$ and fast green. Sections were photographed under the microscopy (TiU, Nikon, Japan). The cell length of 200 randomly selected cells were measured using ImageJ software (http://rsb.info.nih.gov/ $\mathrm{ij} /$ ). Data were analyzed as described above.

\section{RESULTS}

\section{Identification and Characterization of Novel CEP Genes in Rice}

To identify new CEP genes in the rice genome, we searched the Rice Genome Annotation Project Database containing 49,066 gene models (http://rice.plantbiology.msu.edu/index. shtml) using all of the CEP domain sequences of Arabidopsis and rice, and six additional CEP genes were characterized (OsCEP10OsCEP15) (Table S2), which were un-annotated before. Each of newly identified CEP genes encoded a small protein (92-106 amino acids) with a predicted signal peptide at the $\mathrm{N}$-terminal and one CEP domain at the C-terminal (Figure 1). Phylogenetic analysis of $17 C E P$ genes showed that all of the newly identified 


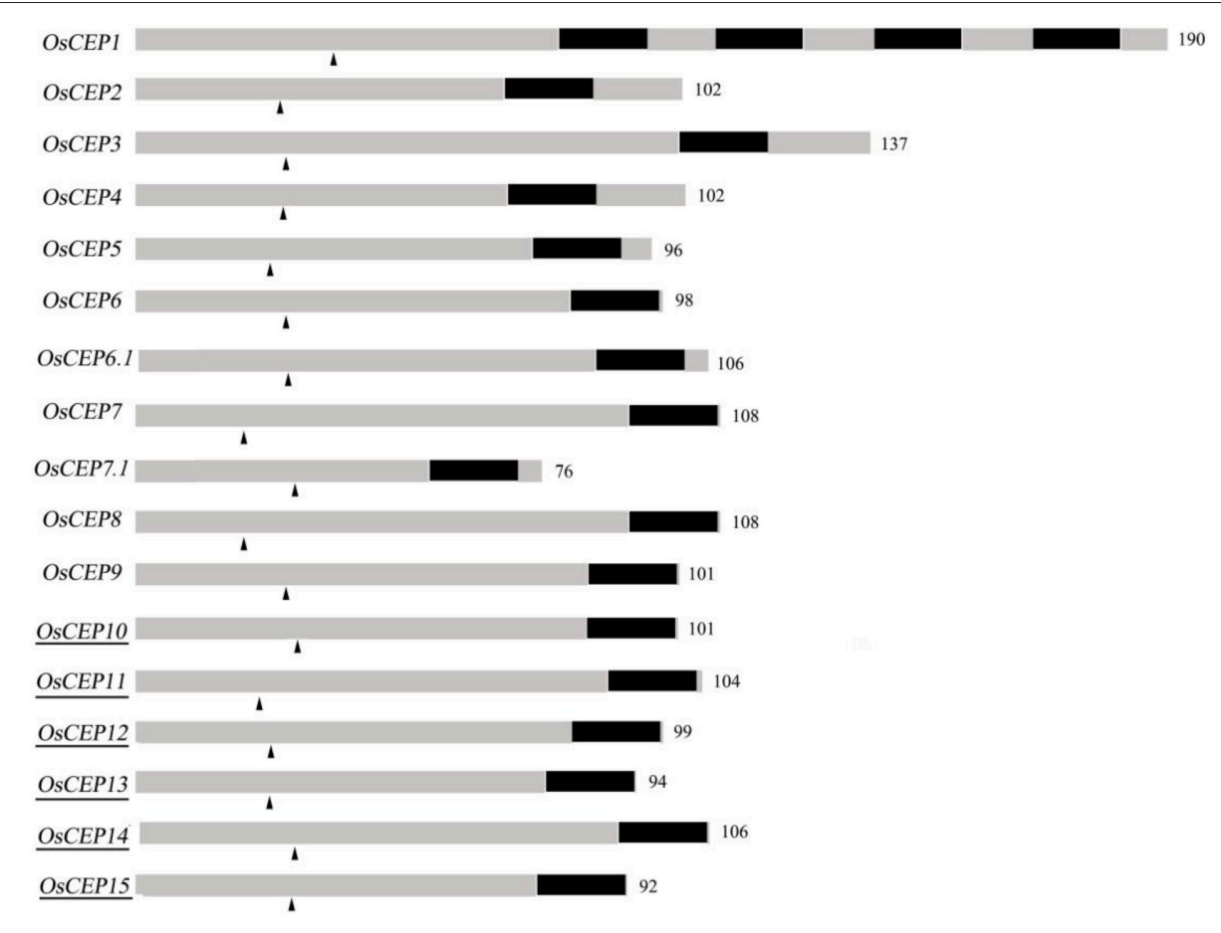

FIGURE 1 | Schematic representation of rice CEP genes. Numbers are number of amino acids of the full length protein; Dark part, CEP domain; arrowhead, predicted signal peptide cleavage site; underscore, new identified CEPs.

CEPs belonged to group II (Figure 2A). Although having the same names, the sequences of OsCEP6 and OsCEP7 identified by Ogilvie et al. (2014) were different from those identified by Delay et al. (2013) (Figures S2A,B). Therefore, we renamed OsCEP6 and OsCEP7 identified by Ogilvie et al. (2014) as OsCEP6.1 and OsCEP7.1, respectively. WebLogo plots showed that the CEP domain of group II was highly conserved among the nine amino acids at the C-terminal region except for the 8th amino acid and exhibited significant divergence in the first six amino acids at the $\mathrm{N}$-terminal region, whereas the CEP domain of group I possessed highly conserved sequences of all 15-amino acids (Figure 2A). However, a divergence of the $\mathrm{N}$-terminus sequences was found in both groups. Chromosome mapping showed that 17 CEPs were located on six out of ten rice chromosomes, and it is notable that OsCEP1, OsCEP2 (4), OsCEP3 and OsCEP11, OsCEP12, OsCEP13, OsCEP14 were distributed in close proximity on chromosome 3 and 5, respectively (Figure 2B).

\section{OsCEP6.1 Exhibited a Tissue-Specific and Hormone- Induced Expression Pattern}

To gain an insight into the expression profiles of the CEP genes in rice, we searched the publicly available gene expression database on Rice qTeller (http://qteller.com/rice/). These in silico data indicated that CEP genes were expressed divergently and exhibited tissue-specific expression patterns. OsCEP1, OsCEP2 (4), OsCEP3, OsCEP12, and OsCEP13 were particularly expressed in root, whereas OsCEP5 and OsCEP6.1 were only expressed in early inflorescences and emerging inflorescences, respectively, displaying similar expression trends as previously reported
(Ogilvie et al., 2014), and making these genes likely candidates for controlling rice reproductive development (Figure S3). To confirm the expression pattern of OsCEP6.1, we performed quantitative RT-PCR analysis in nine different tissues, and found OsCEP6.1 was indeed highly expressed in reproductive tissues, particularly the panicle, which is consistent with Rice qTeller data (Figure 3A, Figure S3). To further investigate OsCEP6.1 expression patterns, we examined its transcript abundance at four developmental stages of the panicle $(<5 \mathrm{~mm}, 10-15 \mathrm{~mm}, 40-$ $50 \mathrm{~mm}$ and heading stage) in both the P64s and 93-11 varieties, showing significant down-regulation at heading stage compared with the first three stages (Figure 3B). Furthermore, we examined the expression pattern of OsCEP6.1 in response to different plant hormones and found it was significantly induced by artificial 6BA, especially at high concentrations, e.g., 10 and $20 \mu \mathrm{M}$, but not low concentrations, consistent with the previous reports (Imin et al., 2013), the significance of which needed further investigation (Figures 3C,D). In addition, nitrogen depletion also significantly induced the expression of OsCEP6.1, consistent with previous reports in Medicago and Arabidopsis (Delay et al., 2013; Imin et al., 2013; Tabata et al., 2014) (Figure 3E).

\section{Exogenous Application of the Synthetic Peptide and Ectopic Expression of OsCEP6.1 are Sufficient to Cause Multiple Phenotypic Variations}

To determine the biological relevance of OsCEP6.1, we first predicted and synthesized its putative 15-amino acid peptide 

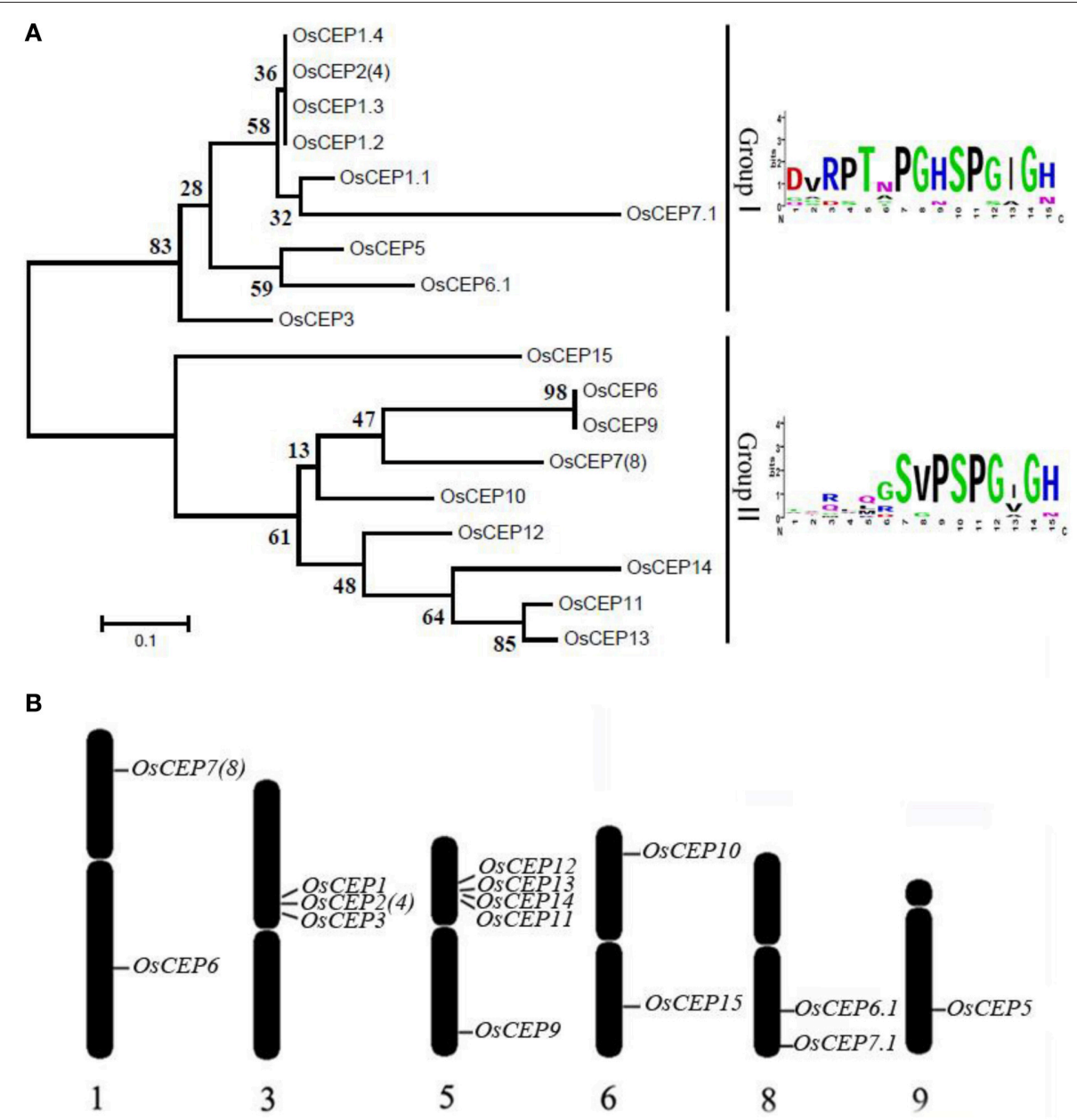

FIGURE 2 | Distribution of CEP genes found in the rice genome. (A) Phylogenetic tree and WebLogo plot were used to show rice CEP gene clustering and the 15-amino acid CEP domain conservation. (B) Chromosomal distribution of CEP genes in the rice genome.

(DSRPTAPGNSPGIGN) (Figure S1) and performed exogenous application experiment. Seedlings subjected to exposure of $10^{-6} \mathrm{M}$ OsCEP6.1 peptide exhibited significantly reduced root and shoot development compared with the control. Specifically, synthesized peptide suppressed the shoot height and root length by approximately 17 and 20\%, respectively (Figure 4A). Next, rice transgenic lines with constitutive expression of OsCEP6.1 were generated under maize ubiquitin promoter. High OsCEP6.1 expression levels were detected in leaves of the overexpression lines and two representative lines (\#5 and \#6) were selected for further analysis (Figure 4B). As expected, overexpression of OsCEP6.1 fundamentally decreased the primary root length and seedling height by approximately $25 \%$ at the early stage in both transgenic lines, consistent with the phenotype caused by the exogenous simulation of synthetic peptide (Figure 4C). At the mature stage, the overexpression lines exhibited dramatically fewer tillers, shorter plant height and smaller flag leaves than those in the control plant ZH17 (Figures 4D-F). In addition, the panicle lengths of the two transgenic lines (\#5and \#6) were 22 and $30 \%$ shorter than those of ZH17, respectively (Figure 5A), and the number of primary and secondary rachis branches was also significantly fewer compared with the control, with 30 and $83 \%$ reduction, respectively (Figure 5B). Furthermore, constitutive expression of OsCEP6.1 in rice negatively affected agronomic traits of the grain, including grain number per panicle, grain length, grain width and 1000 grain weight, which were severely reduction by $60,7,4$, and $19 \%$, respectively, in the transgenic lines (\#5and \#6) compared with those in $\mathrm{ZH} 17$ (Figures 5A, 6A,B).

\section{Overexpression of OsCEP6.1 Decreased Cell Size, Not Cell Number in Rice Seeds}

To investigate the causes underlying the phenotypic variation of grain size between transgenic and wild-type plants, we performed histological analysis to examine the stage transformation of endosperm in T2 transgenic lines, which was closely correlated with rice seed size (Folsom et al., 2014). Unexpectedly, the cellularizition of endosperm was faster in the control than in the transgenic lines at 2 days after pollination (Figure S4A), which was confirmed by the expression patterns of the syncytial stage specific MADS-box genes OsMADS82 and OsMADS87 (Figure S4B). However, the endosperm of ZH17 (control) was 
A

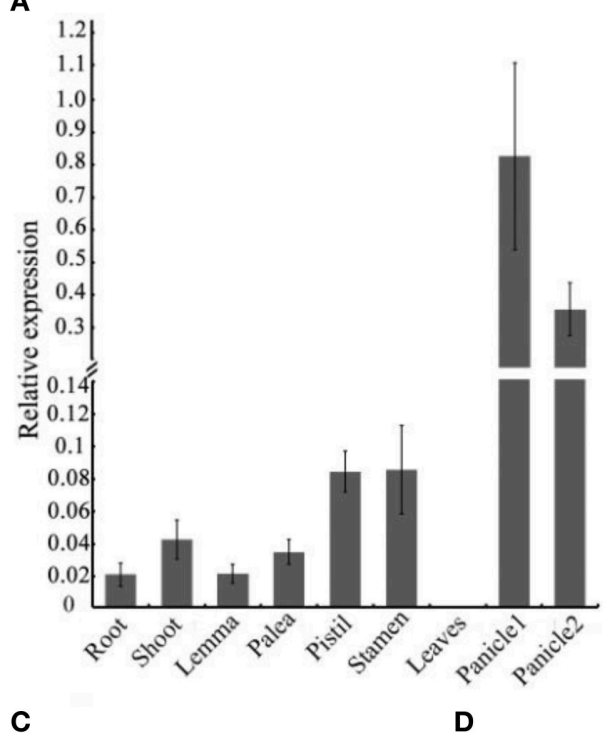

B

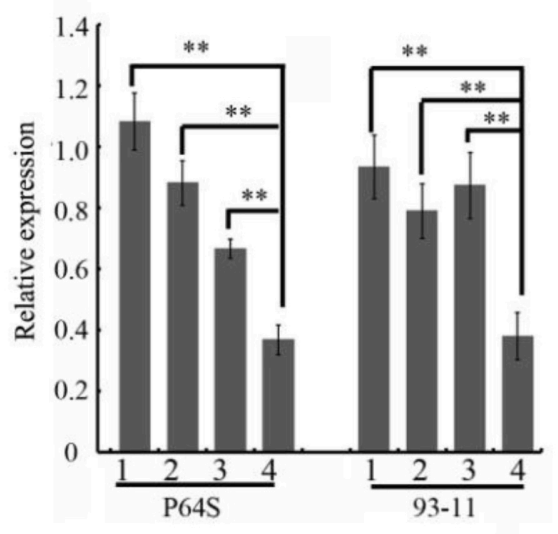

E

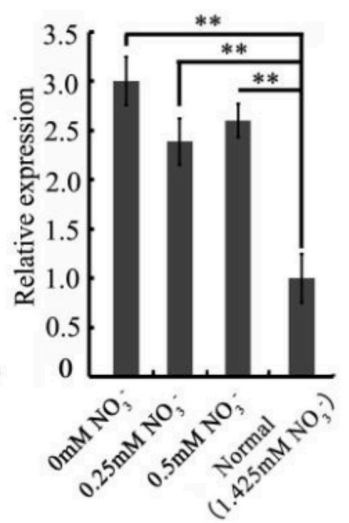

FIGURE 3 | The spatio-temporal expression patterns of OsCEP6.1. (A) Quantitative RT-PCR analysis revealed that OsCEP6.1 was highly expressed in the panicle among nine tissues of ZH17, including root, shoot, lemma, palea, stamen, pistil, leaf and panicles. panicle1: 40-50 mm panicles; panicle2: panicles at heading stage. (B) Quantitative RT-PCR analysis showed that the expression level of OsCEP6.1 was significantly higher at the first three stages of panicles compared with the heading stage in both P64S and 93-11. 1: <5 mm panicles; 2: 10-15 mm panicles; 3: 40-50 mm panicles, 4: panicles at heading stage. (C) The expression level of OsCEP6.1 was significantly induced by 6-BA application. The 6-day-old seedlings were treated with different phytohormones $(10 \mu \mathrm{M}$ NAA, $10 \mu \mathrm{M}$ 6-BA, $10 \mu \mathrm{M}$ GA, $100 \mu \mathrm{M}$ ABA, $1 \mu \mathrm{M}$ BR, $100 \mu \mathrm{M}$ MeJA, and $50 \mu \mathrm{M}$ ACC). (D) The expression patterns of OsCEP6.1 was significantly induced under $10 \mu \mathrm{M}$ 6-BA compared with other concentration applications. The 6-day-old seedlings were treated with 0, 1, 3, 5, 10, and, $20 \mu \mathrm{M}$ 6-BA. (E) The expression level of OsCEP6.1 was increased under low nitrate concentration. The 6-day-old seedlings were transferred to the nutrient solutions with different nitrate concentration, and the root was collected 3 days after transfer. ${ }^{\star \star} P<0.01$.

fundamentally larger than that of the OsCEP6.1 overexpression lines at the respective developmental stages, which was inconsistent with the previous report that the precocious cellularization of endosperm leads to small seeds (Kang et al., 2008; Ishimaru et al., 2013; Folsom et al., 2014). Interestingly, the expression level of cellularization stage-specific STRACH SYNTHASE II (SSII) was significantly higher in transgenic lines than in $\mathrm{ZH} 17$ at early stages but lower at later stages (Figure S4B), motivating us to explore whether the starch was altered by constitutive expression of OsCEP6.1. Unfortunately, neither the starch granule nor the starch arrangements changed significantly in transgenic lines compared with wild type plants detected by scanning electron microscopy (Figure S5). Because the previous study reported that rice grain size is often greatly limited by the restriction of glume (Shomura et al., 2008), we next focused on the development of glume and compared the cell size between these two plants (Figure 7). Scanning electron microscopy observation revealed that the distance between two adjacent tubercles and the size of inner epidermal cells of the lemma (including cell length and width) were significantly smaller in the OsCEP6.1 overexpression lines than in wild type plants (Figures 7A,B), and statistical analysis further confirmed our observation (Figures 7C-E). In addition, histological analysis of glume sectioning found that the cell length was reduced for most cells at outer parenchyma layer of the glume in the OsCEP6.1 transgenic line than that in wild type plant (Figure 7F). However, no significant difference in the cell number was detected in the seeds between the 
A

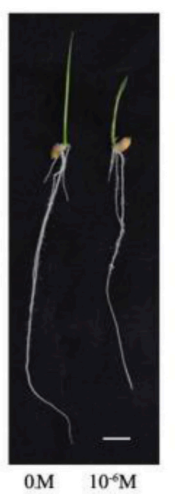

C

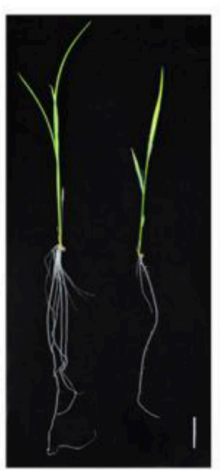

ZH17 \#5

E

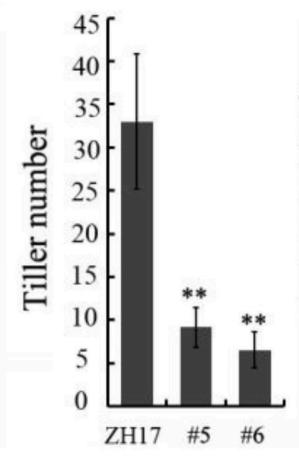

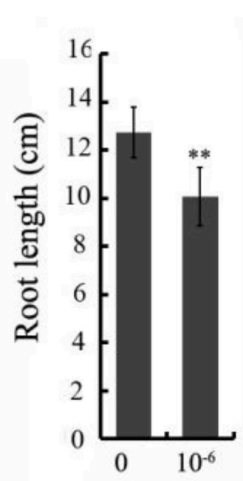

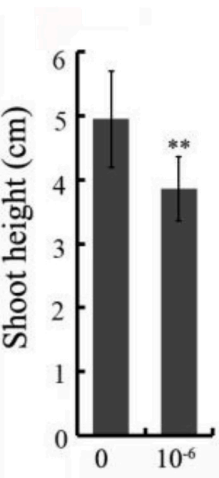

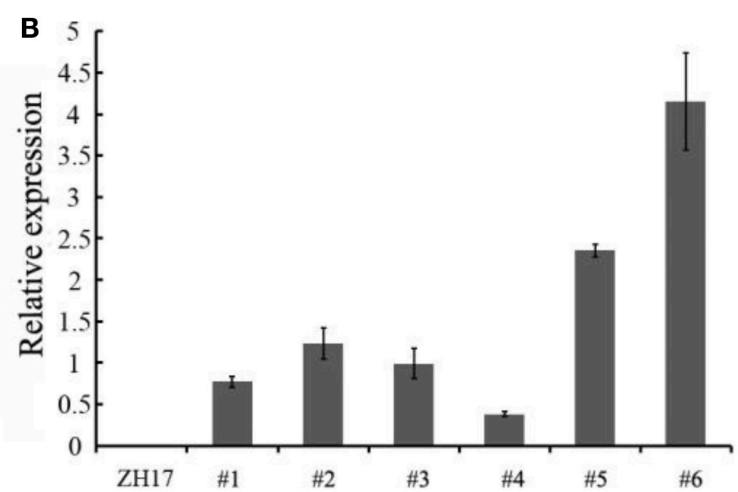

ZH17
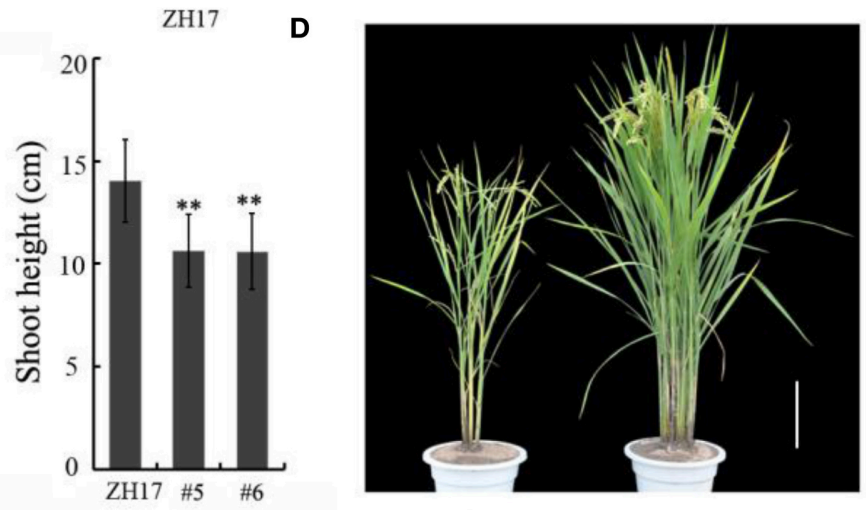

\#5

ZH17

F
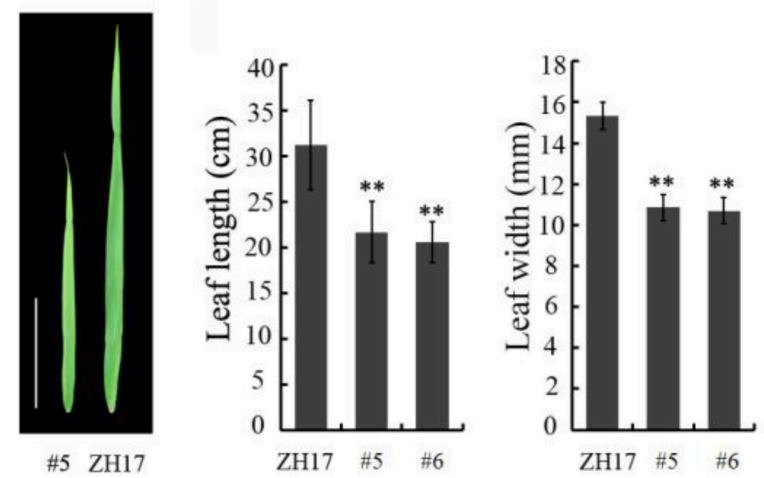

FIGURE 4 | Overexpression of OSCEP6.1 negatively affected the vegetative growth of rice. (A) Comparison of the root length and shoot height between the control and seedlings with synthetic CEP at the 8-day-old stage. The growth of shoot and root was significantly repressed by synthetic CEP peptide, by 17 and $20 \%$, respectively. Bar $=1 \mathrm{~cm}$. The values are means $\pm S D(n=18),{ }^{* *} P<0.01$. (B) Quantitative RT-PCR analysis revealed the high expression level of OsCEP6.1 in six overexpression lines at the T0 generation, particularly lines \#5 and \#6. (C) Comparison of the root length and shoot height of the transgenic lines (\#5) and control at the 14-day-old seedlings. The growth of shoot and root was significantly repressed by approximately $25 \%$ in the transgenic line compared with the control. Bar $=$ $2 \mathrm{~cm}$. The values are means $\pm S D(n \geq 10)$, ${ }^{\star *} P<0.01$. (D) Overexpression of OSCEP6. 1 leads to phenotypic variation at the mature stage including plant stature and panicle architecture. Bar $=20 \mathrm{~cm}$. (E) OsCEP6.1 overexpression lines exhibited significantly fewer tillers and shorter height compared with those of the control. (F) Both the length and width of flag leaves were significantly smaller in the transgenic line (\#5 and \#6) than those in the control. Bar $=10 \mathrm{~cm}$. The values are means $\pm S D$ $(n \geq 12),{ }^{* *} P<0.01$.

transgenic lines and the wild type (Table S3), although the expression levels of five putative G1/S-phase genes (CDKA1, CAK1, CAK1A, CYCT1, and CYCD4), and three G2/M-phase genes (CYCIaZm, CDKB, and CYCB2.1) were down-regulated in the panicle of two transgenic lines (\#5and \#6) compared with the controls (Figure 8, Figure S6), suggesting that the changes of the cell-cycle related genes expression might be the secondary effects of CEP6.1 overexpression but not the reason for seed size variation. Therefore, the above results collectively reveal that cell size, not cell number was significantly reduced because of constitutive expression of OsCEP6.1 in rice, which resulted in the reduced grain size of rice in transgenic lines. 

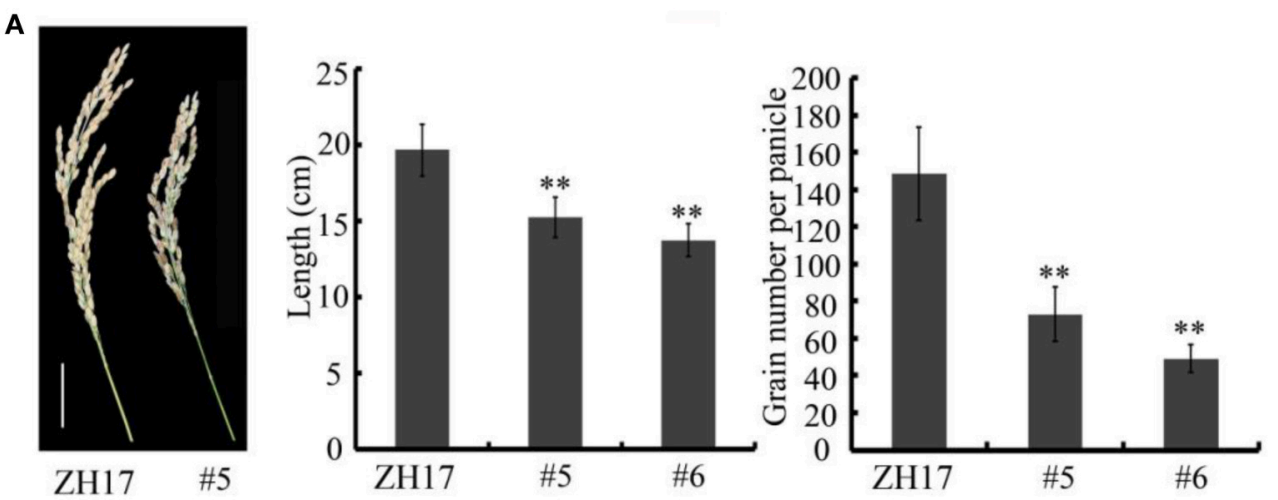

B

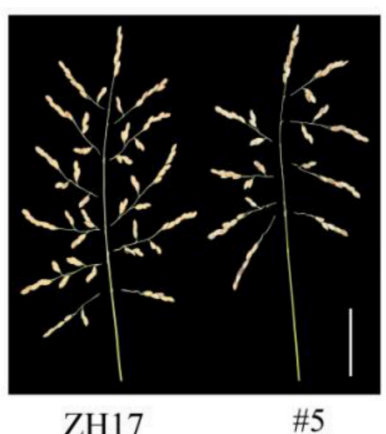

C

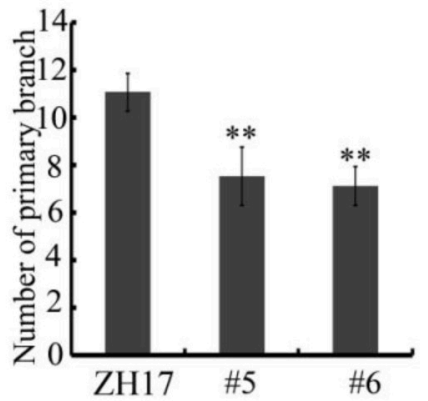

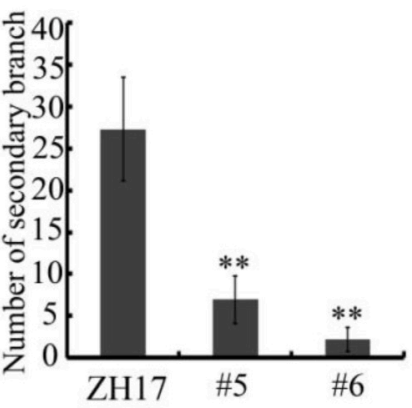

FIGURE 5 | Overexpression of OsCEP6.1 modulates panicle architecture in rice. (A) OSCEP6.1 overexpression lines exhibited shorter panicles and fewer grains per panicle compared with the control (ZH17). Bar $=5 \mathrm{~cm}$. The values are means $\pm \mathrm{SD}(n \geq 12),{ }^{* *} P<0.01$. (B) Panicle branching. Bar $=5 \mathrm{~cm}$. (C) The number of primary branches and secondary branches per panicle were significantly fewer in two transgenic lines (\#5and \#6) than in the control, the values are means $\pm \mathrm{SD}(n \geq 12),{ }^{* *} P<0.01$

A

ZH17

\#5

\#6

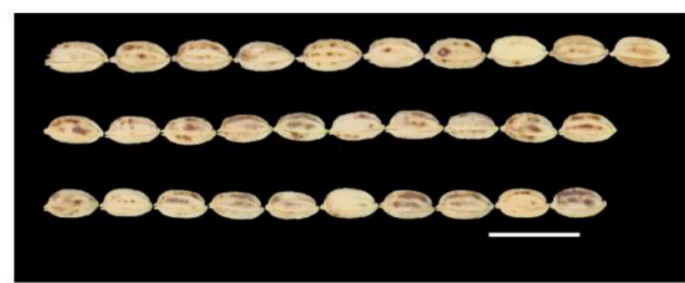

ZH17

\#5

\#6

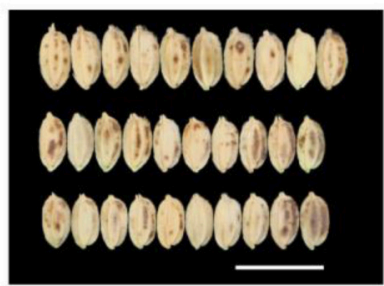

B
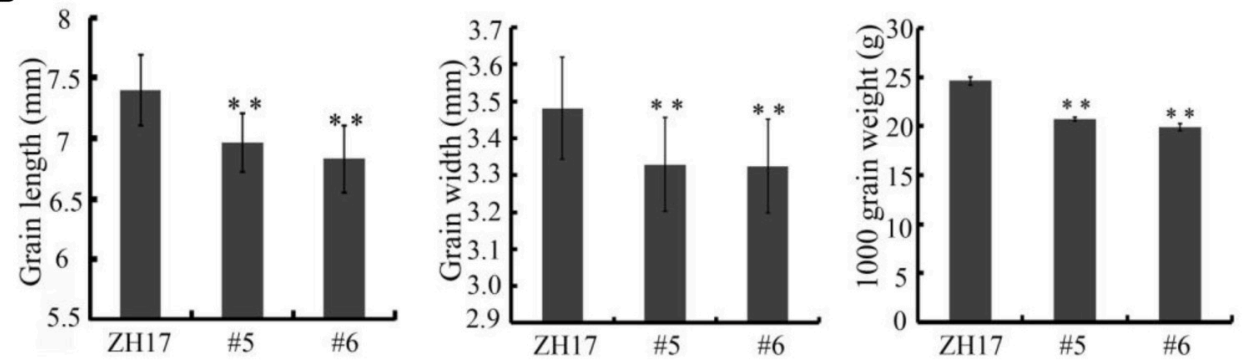

FIGURE 6 | Overexpression of OsCEP6.1 decreases grain size in rice. (A) Phenotypic variation between the control and OsCEP6.1 transgenic line in both gain length and width. (B) Constitutive expression of OSCEP6.1 significantly decreased seed length, seed width and 1000- grain weight, with 7, 4, and 19\% reduction, respectively. Bar $=1 \mathrm{~cm}$. The values are means $\pm \mathrm{SD}(n \geq 90),{ }^{* *} P<0.01$. 
A

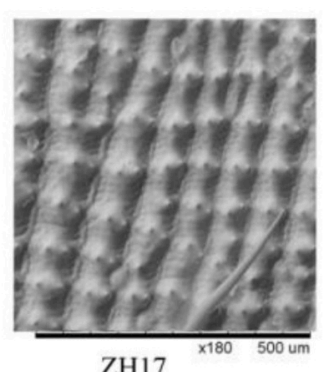

ZH17

B

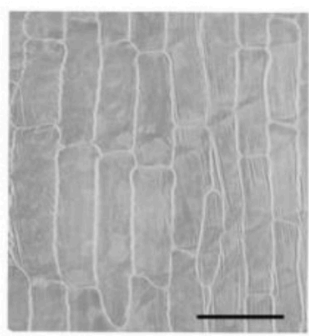

ZH17

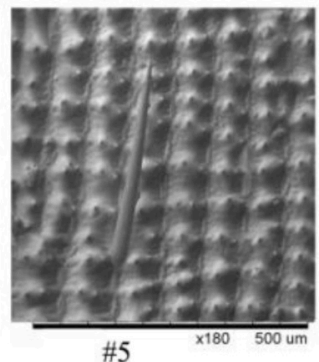

$\# 5$

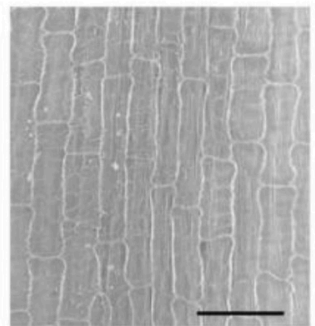

$\# 5$

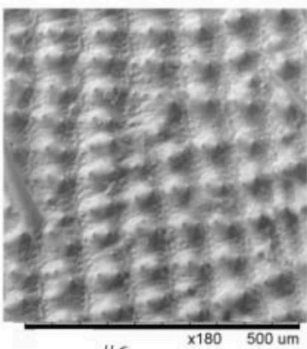

\#6

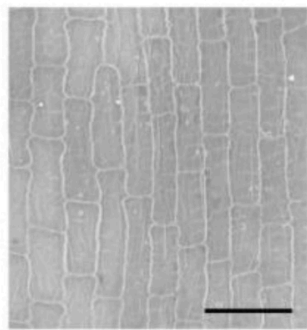

\#6
C

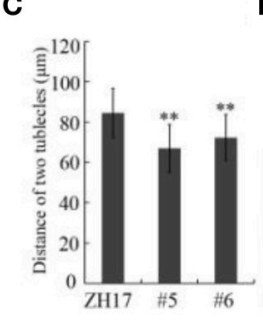

D ${ }^{12}$

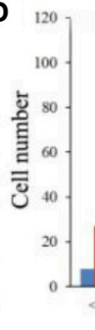

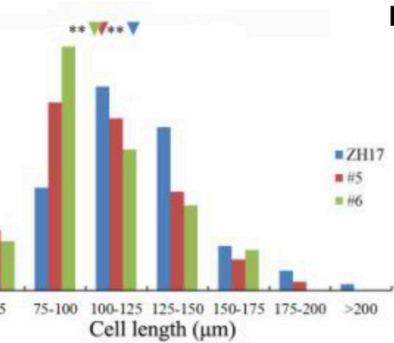

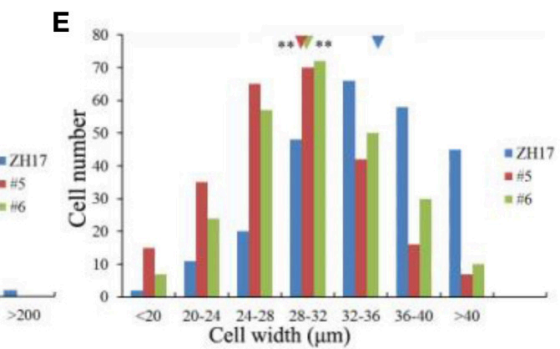

$\mathbf{F}$
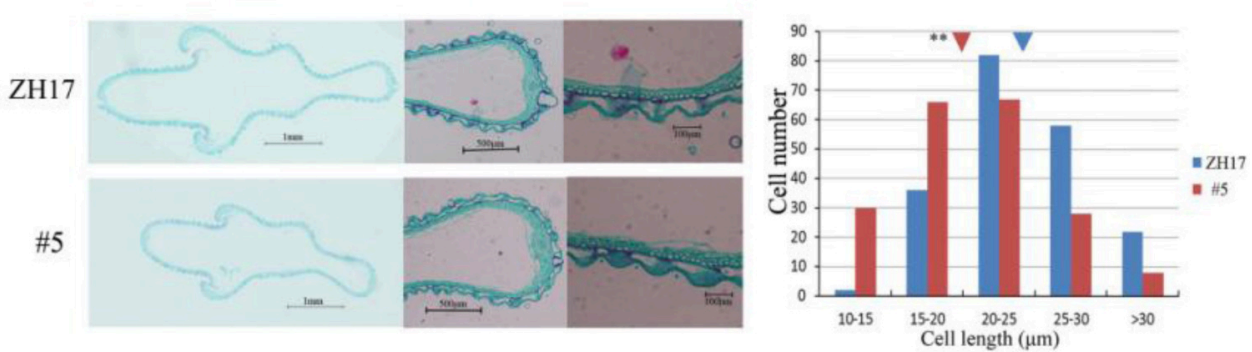

FIGURE 7 | Scanning electron microscopy analysis of OsCEP6.1 overexpression lines and the control. (A) Scanning electron microscopy analysis revealed that the distance between two adjacent tubercles on the outer spikelet hull surface was significantly shortened compared with the control $(\mathrm{ZH} 17)$. Bar $=100 \mu \mathrm{m}$, $\times 180$. (B) Scanning electron microscopy observation showed that the size of the lemma inner epidermal cell is smaller in the transgenic line than that in the control. Bar $=100 \mu \mathrm{m}, \times 250$. (C-E) Statistical analysis of the distance between two adjacent tubercles $(n=200)$, cell length $(n=250)$ and cell width $(n=250)$ showed that all of them were significantly reduced by the overexpression of OSCEP6.1. The inverted triangles present the average cell length and width, the values are means \pm SD. ${ }^{* *}$ Indicates significance of cell length and width between the transgenic line and the control at the $P=0.01$ level. (F) Histological analyses showed that the cell length of the outer parenchymal cell layers of the spikelet hulls is significantly larger in $\mathrm{ZH} 17$ than in the transgenic line. Blue and red inverted triangles show the average cell width of $\mathrm{ZH} 17$ and transgenic line (\#5), respectively, and the values are means $\pm \mathrm{SD}(n=200)$, ${ }^{* *} P<0.01$.

\section{DISCUSSION}

Previous reports have predicted more than 900 putative CEP peptides across the plant genome that predominantly occur in gymnosperm and angiosperm plants, but their biological significance remains largely unknown (Ohyama et al., 2008; Delay et al., 2013; Imin et al., 2013; Roberts et al., 2013;
Ogilvie et al., 2014; Tabata et al., 2014; Mohd-Radzman et al., 2015). In this study, we performed a genome-wide survey of CEP genes in rice based on the CEP domain conservation and identified six additional CEP genes in rice, all belonging to Group II (Figure 2A). Of the previously identified eleven rice CEP members, the full length cDNA sequence of OsCEP2 (EAY90324.1, 93-11) was likely the same 

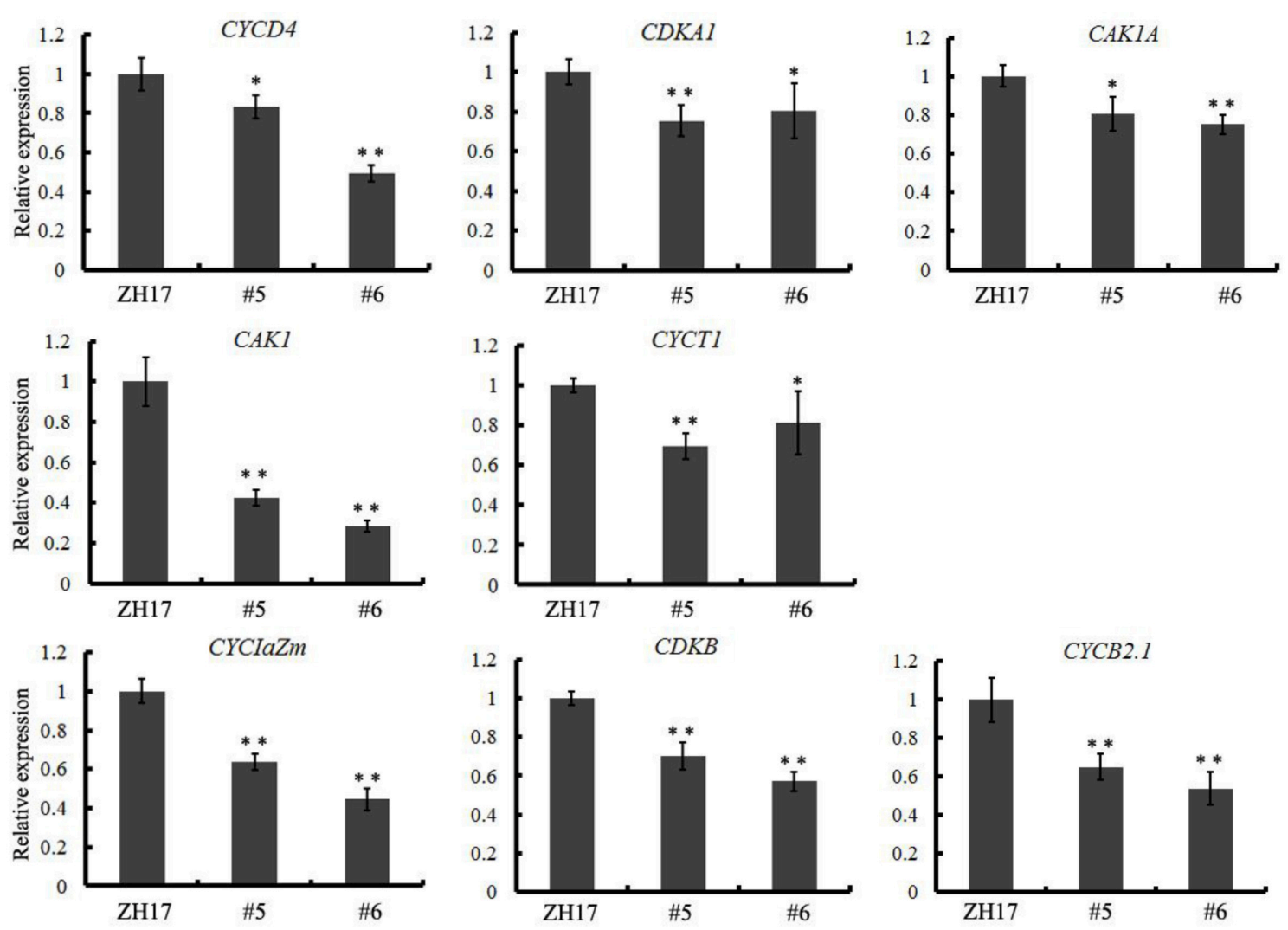

FIGURE 8 | Quantitative RT-PCR analysis revealed that eight cell-cycle-related genes, including five G1/S-phase genes (CDKA1, CAK1, CAK1A, CYCT1, and CYCD4) and three G2/M-phase genes (CYClaZm, CDKB, and CYCB2.1), were significantly down-regulated in the transgenic line compared with the control. The expression levels were determined using $6-8 \mathrm{~cm}$ young panicles from at least five plants, the values are means $\pm S D$, ${ }^{*} P<0.05$, ${ }^{* *} P<0.01$.

as that of OsCEP4 (AAP04189.1, Nipponbare), because they were mapped to the same position on the short arm of chromosome 3 with only one SNP between them, which was most likely caused by different subspecies (Figure 2B, Figure S7A). Similarly, OsCEP7 (Os01g0203400.1) identified from Nipponbare was assumed to be OsCEP8 (EAY72936.1) from 93 to 11 based on sequence similarity and consistent mapping position (Figure 2B, Figure S7B). In addition, we renamed OsCEP6 and OsCEP7, which were identified by Ogilvie et al. (2014), as OsCEP6.1 and OsCEP7.1, respectively, because of their sequence differences compared with previously identified OsCEP6 and OsCEP7 (Figure S2B). Thus, 15 CEP genes in total were identified in rice genome and exhibited a biased distribution on six chromosomes (Figure 2B). Specifically, OsCEP11, 12, 13, and 14 were tandemly arrayed in the middle of the short arm of chromosome 5, whereas OsCEP1, 2(4) and 3 were clustered proximally to the centromere of chromosome 3 .

The importance of CEP genes in cell-to-cell communication in plants has been documented, which are involved in the regulation of plant growth and development (Ohyama et al., 2008; Delay et al., 2013; Roberts et al., 2013; Ogilvie et al., 2014; MohdRadzman et al., 2015), e.g., constitutive expression of AtCEP3 inhibits primary root development in transgenic Arabidopsis, whereas the silencing of AtCEP3 promotes root growth under the high salt concentration and nitrogen-limiting conditions (Delay et al., 2013). In Medicago ectopic expression of MtCEP1 reduces the lateral root number, but the simultaneous down-regulation of $M t C E P 1,2,5$, and 11 results in a contrasting phenotype. However, knockdown of MtCEP1 alone does not show any significant phenotypic variation, which is probably due to the functional redundancy (Ishikawa et al., 2011; Imin et al., 2013; Mohd-Radzman et al., 2015). In this study, the tissue-specific expression pattern and the overexpression experiment indicated that OsCEP6.1 might be involved in the regulation of panicle development, causing reduced plant height, tiller number, grain number and grain size, but the starch granule and the starch arrangement were not affected in the OsCEP6.1 overexpression lines. Although OsCEP6.1 was specifically expressed in rice panicles and ectopic expression of OsCEP6.1 caused pleiotropic effects on plant reproductive growth, further efforts are still needed to verify its specific function on ear development. However, this is the first report regarding the CEP gene participating in the regulation of proliferative tissue development in rice. Therefore, we can conclude that OsCEP6.1 is sufficient but not necessary to repress plant development based on our present data. OsCEP5 and OsCEP6.1 exhibit similar expression patterns 
among different tissues (Ogilvie et al., 2014), suggesting that they might have redundant functions, thus phenotypic variation of the panicle is expected in further analysis upon the knockdown of both CEPs.

The interesting phenotypic variation motivated us to further explore the underlying causes and found that reduced cell size but not cell number leads to small grain size, although eight cell-cycle-related genes were down-regulated in the OsCEP6.1 overexpression lines (Figure 8). Further analysis found that five out of 17 grain-size-related genes (GW2, GW5, GS3, GL3.1, and SG1) were significantly down-regulated in OsCEP6.1 constitutive expression lines (Figure S8), through which OsCEP6.1 might contribute to the delayed development of rice grain. Previous studies have suggested that precocious cellularization of endosperm will always result in small endosperm because of few free nuclei (Ishikawa et al., 2011; Zhou et al., 2013; Folsom et al., 2014), but our histological analysis exhibited opposite situation in that overexpression of OsCEP6.1 caused the slower cellularizaiton of endosperm and smaller seeds in transgenic line compared with the control. This phenotypic variation maybe be involved in the downregulation of cell-cycle-related genes, which results in delayed growth at all developmental stages. Together, this study identified six new CEP genes in the rice genome and verified that overexpression of OsCEP6.1 can result inpleiotropic effects on growth decreasing in rice, which sheds light on the understanding of the potential role of CEP genes during rice development.

\section{AUTHOR CONTRIBUTIONS}

ZN, MX conceived the project. ZS, TW, GX, and HL collected the plant materials, ZS and TW performed the experiment, $\mathrm{YL}, \mathrm{MZ}$, and RX analyzed data. MX and NZ wrote the manuscript.

\section{ACKNOWLEDGMENTS}

We thank Dr. Zuofeng Zhu and Dr. Tao Zhao for the genetic transformation of rice. This work was supported by the National Natural Science Foundation of China (31471479, 31230054 and 31200914) and Chinese Universities Scientific Fund (15054038).

\section{SUPPLEMENTARY MATERIAL}

The Supplementary Material for this article can be found online at: http://journal.frontiersin.org/article/10.3389/fpls.2016. 00228

\section{Figure S1 | MS data of synthetic CEP peptides (DSRPTAPGNSPGIGN).}

Figure S2 | Nucleotide sequences alignment of the rice CEP genes. (A) The sequences of OSCEP1, 2, 3, and 5 identified in Ogilvie's paper (red) are the same as those identified by Delay et al. (2013) and Roberts et al. (2013) (black). (B) The sequences of OSCEP6 and 7 identified in Ogilvie's paper (red) are different from those of OsCEP6 and 7 identified by Delay et al. (2013) and Roberts et al. (2013) (black).

Figure S3 | Expression patterns of 14 rice CEPs as determined by Rice qTeller (http://qteller.com/rice/).

Figure S4 | Histological analysis of the rice grain and expression profile of syncytial and cellularization stage specific genes. (A) The OSCEP6. 1 overexpression line exhibited slower cellularization than that of the control. (B) The expression level of syncytial stage specific MADS-box genes (OsMADS82and OSMADS87, but not AGL36) was significantly higher in the transgenic line than in the control at 2 DAP, whereas the expression level of the cellularization stage specific gene STRACH SYNTHASE II (SSII) was higher at 5 DAP but lower at 8 DAP in the transgenic line compared with the control.

Figure S5 | Scanning electron microscopy analysis revealed that neither the starch granule nor the starch arrangement was obviously different between the control (ZH17) and the transgenic lines (\#5).

Figure 56 | Quantitative RT-PCR analysis revealed that eight cell-cycle-related genes, including five G1/S-phase genes (CDKA1, CAK1, CAK1A, CYCT1, and CYCD4) and three G2/M-phase genes (CYClaZm, CDKB and CYCB2.1), were significantly down-regulated in the transgenic line compared with the control. The expression levels were determined using $6-8 \mathrm{~cm}$ young panicles from at least five plants, the values are means $\pm S D$, ${ }^{*} P<0.05,{ }^{*} P<0.01$. The inner control genes was the UBQ gene.

Figure S7 | (A) OSCEP2 (EAY90324.1, 93-11) and OSCEP4 (AAP04189.1, Nipponbare) have only one SNP in their nucleotide sequences. (B) OsCEP7 (Os01g0203400.1, Nipponbare) and OsCEP8 (EAY72936.1, 93-11) have 98\% similarity between each other.

Figure S8 | Quantitative RT-PCR analysis revealed that five grain size related genes (GL3.1, SG1, GW2, GW5, and GS3) were down-regulated in the two transgenic lines (\#5and \#6) compared with the control. Expression levels were determined using $6-8 \mathrm{~cm}$ young panicles from at least five plants, the values are means $\pm \mathrm{SD},{ }^{*} P<0.05,{ }^{* *} P<0.01$.

Table S1 | Primer pairs used in this study.

Table S1 | The rice CEP genes identified in the previous study (Delay et al., 2013; Roberts et al., 2013; Ogilvie et al., 2014) and our study.

Table S2 | Cell size and cell number in the seeds.

\section{REFERENCES}

Ashikari, M., Sakakibara, H., Lin, S., Yamamoto, T., Takashi, T., Nishimura, A., et al. (2005). Cytokinin oxidase regulates rice grain production. Science 309, 741-745. doi: 10.1126/science.1113373

Cheng, A. X., Xiang, C. Y., Li, J. X., Yang, C. Q., Hu, W. L., Wang, L. J., et al. (2007). The rice (E)-beta-caryophyllene synthase (OsTPS3) accounts for the major inducible volatile sesquiterpenes. Phytochemistry 68, 1632-1641. doi: 10.1016/j.phytochem.2007.04.008

Crooks, G. E., Hon, G., Chandonia, J. M., and Brenner, S. E. (2004). WebLogo: a sequence logo generator. Genome Res. 14, 1188-1190. doi: 10.1101/gr.849004

Dai, X., Wang, Y., Yang, A., and Zhang, W. H. (2012). OsMYB2P-1, an R2R3 MYB transcription factor, is involved in the regulation of phosphate-starvation

responses and root architecture in rice. Plant Physiol. 159, 169-183. doi: 10.1104/pp.112.194217

Delay, C., Imin, N., and Djordjevic, M. A. (2013). CEP genes regulate root and shoot development in response to environmental cues and are specific to seed plants. J. Exp. Bot. 64, 5383-5394. doi: 10.1093/jxb/ert332

Fan, C. H., Xing, Y. Z., Mao, H. L., Lu, T. T., Han, B., Xu, C. G., et al. (2006). GS3, a major QTL for grain length and weight and minor QTL for grain width and thickness in rice, encodes a putative transmembrane protein. Theor. Appl. Genet. 112, 1164-1171. doi: 10.1007/s00122-006-0218-1

Folsom, J. J., Begcy, K., Hao, X. J., Wang, D., and Walia, H. (2014). Rice fertilization-independent endosperm 1 regulates seed size under heat stress by controlling early endosperm development. Plant Physiol. 165, 238-248. doi: 10.1104/pp.113.232413 
Imin, N., Mohd-Radzman, N. A., Ogilvie, H. A., and Djordjevic, M. A. (2013). The peptide-encoding CEP1 gene modulates lateral root and nodule numbers in Medicago truncatula. J. Exp. Bot. 64, 5395-5409. doi: 10.1093/jxb/e rt369

Ishikawa, R., Ohnishi, T., Kinoshita, Y., Eiguchi, M., Kurata, N., and Kinoshita, T. (2011). Rice interspecies hybrids show precocious or delayed developmental transitions in the endosperm without change to the rate of syncytial nuclear division. Plant J. 65, 798-806. doi: 10.1111/j.1365-313X.2010.0 4466.x

Ishimaru, K., Hirotsu, N., Madoka, Y., Murakami, N., Hara, N., Onodera, H., et al. (2013). Loss of function of the IAA-glucose hydrolase gene TGW6 enhances rice grain weight and increases yield. Nat. Genet. 45, 707-711. doi: 10.1038/ng.2612

Kang, I. H., Steffen, J. G., Portereiko, M. F., Lloyd, A., and Drews, G, N. (2008). The AGL62 MADS domain protein regulates cellularization during endosperm development in Arabidopsis. Plant Cell 20, 635-647. doi: 10.1105/tpc.107.055137

Katsir, L., Davies, K. A., Bergmann, D. C., and Laux, T. (2011). Peptide signaling in plant development. Curr. Biol. 21, R356-R364. doi: 10.1016/j.cub.2011.03.012

Kondo, T., Sawa, S., Kinoshita, A., Mizuno, S., Kakimoto, T., Fukuda, H., et al. (2006). A plant peptide encoded by CLV3 identified by in situ MALDI-TOF MS analysis. Science 313, 845-848. doi: 10.1126/science.1128439

Kurakawa, T., Ueda, N., Maekawa, M., Kobayashi, K., Kojima, M., Nagato, Y., et al. (2007). Direct control of shoot meristem activity by a cytokinin-activating enzyme. Nature 445, 652-655. doi: 10.1038/nature05504

Lee, T. M., Lur, H. S., Lin, Y. H., and Chu, C. (1996). Physiological and biochemical changes related to methyl jasmonate-induced chilling tolerance of rice (Oryza sativa L) seedlings. Plant Cell Environ. 19, 65-74. doi: 10.1111/j.1365-3040.1996.tb00227.x

Li, J. M., Thomson, M., and McCouch, S. R. (2004). Fine mapping of a grain-weight quantitative trait locus in the pericentromeric region of rice chromosome 3. Genetics 168, 2187-2195. doi: 10.1534/genetics.104.034165

Li, X. Y., Qian, Q., Fu, Z. M., Wang, Y. H., Xiong, G. S., Zeng, D. L., et al. (2003). Control of tillering in rice. Nature 422, 618-621. doi: 10.1038/nature01518

Li, Y., Fan, C., Xing, Y., Jiang, Y., Luo, L., Sun, L., et al. (2011). Natural variation in GS5 plays an important role in regulating grain size and yield in rice. Nat. Genet. 43, 1266-1269. doi: 10.1038/ng.977

Mao, H. L., Sun, S. Y., Yao, J. L., Wang, C. R., Yu, S. B., Xu, C. G., et al. (2010). Linking differential domain functions of the GS3 protein to natural variation of grain size in rice. Proc. Natl. Acad. Sci. U.S.A. 107, 19579-19584. doi: $10.1073 /$ pnas. 1014419107

Matsubayashi, Y. (2011). Post-translational modifications in secreted peptide hormones in plants. Plant Cell Physiol. 52, 5-13. doi: 10.1093/pcp/pcq169

Mohd-Radzman, N. A., Binos, S., Truong, T. T., Imin, N., Mariani, M., and Djordjevic, M. A. (2015). Novel MtCEP1 peptides produced in vivo differentially regulate root development in Medicago truncatula. J. Exp. Bot. 66, 5289-5300. doi: 10.1093/jxb/erv008

Nayar, S., Sharma, R., Tyagi, A. K., and Kapoor, S. (2013). Functional delineation of rice MADS29 reveals its role in embryo and endosperm development by affecting hormone homeostasis. J. Exp. Bot. 64, 4239-4253. doi: $10.1093 /$ jxb/ert231

Ogilvie, H. A., Imin, N., and Djordjevic, M. A. (2014). Diversification of the C-TERMINALLY ENCODED PEPTIDE (CEP) gene family in angiosperms, and evolution of plant-family specific CEP genes. BMC Genomics 15:870. doi: 10.1186/1471-2164-15-870

Ohyama, K., Ogawa, M., and Matsubayashi, Y. (2008). Identification of a biologically active, small, secreted peptide in Arabidopsis by in silico gene screening, followed by LC-MS-based structure analysis. Plant J. 55, 152-160. doi: 10.1111/j.1365-313X.2008.03464.X
Qi, P., Lin, Y. S., Song, X. J., Shen, J. B., Huang, W., Shan, J. X., et al. (2012). The novel quantitative trait locus GL3.1 controls rice grain size and yield by regulating Cyclin-T1;3. Cell Res. 22, 1666-1680. doi: 10.1038/cr.2012.151

Roberts, I., Smith, S., De Rybel, B., Van Den Broeke, J., Smet, W., De Cokere, S., et al. (2013). The CEP family in land plants: evolutionary analyses, expression studies, and role in Arabidopsis shoot development. J. Exp. Bot. 64, 5371-5381. doi: $10.1093 / \mathrm{jxb} / \mathrm{ert} 331$

Shomura, A., Izawa, T., Ebana, K., Ebitani, T., Kanegae, H., Konishi, S., et al. (2008). Deletion in a gene associated with grain size increased yields during rice domestication. Nat. Genet. 40, 1023-1028. doi: 10.1038/ng.169

Song, X. J., Huang, W., Shi, M., Zhu, M. Z., and Lin, H. X. (2007). A QTL for rice grain width and weight encodes a previously unknown RING-type E3 ubiquitin ligase. Nat. Genet. 39, 623-630. doi: 10.1038/ng2014

Tabata, R., Sumida, K., Yoshii, T., Ohyama, K., Shinohara, H., and Matsubayashi, Y. (2014). Perception of root-derived peptides by shoot LRR-RKs mediates systemic N-demand signaling. Science 346, 343-346. doi: $10.1126 /$ science. 1257800

Tamura, K., Peterson, D., Peterson, N., Stecher, G., Nei, M., and Kumar, S. (2011). MEGA5: molecular evolutionary genetics analysis using maximum likelihood, evolutionary distance, and maximum parsimony methods. Mol. Biol. Evol. 28 2731-2739. doi: 10.1093/molbev/msr121

Tanaka, A., Nakagawa, H., Tomita, C., Shimatani, Z., Ohtake, M., Nomura, T., et al. (2009). BRASSINOSTEROID UPREGULATED1, encoding a helixloop-helix protein, is a novel gene involved in brassinosteroid signaling and controls bending of the lamina joint in rice. Plant Physiol. 151, 669-680. doi: 10.1104/pp.109.140806

Wang, C., Ying, S., Huang, H. J., Li, K., Wu, P., and Shou, H. X. (2009). Involvement of OsSPX1 in phosphate homeostasis in rice. Plant J. 57, 895-904. doi: 10.1111/j.1365-313X.2008.03734.X

Wang, S. K., Wu, K., Yuan, Q. B., Liu, X. Y., Liu, Z. B., Lin, X. Y., et al. (2012). Control of grain size, shape and quality by OsSPL16 in rice. Nat. Genet. 44, 950-954. doi: 10.1038/ng.2327

Weng, J. F., Gu, S. H., Wan, X. Y., Gao, H., Guo, T., Su, N., et al. (2008). Isolation and initial characterization of GW5, a major QTL associated with rice grain width and weight. Cell Res. 18, 1199-1209. doi: 10.1038/cr.2008.307

Wu, C. Y., Trieu, A., Radhakrishnan, P., Kwok, S. F., Harris, S., Zhang, K., et al. (2008). Brassinosteroids regulate grain filling in rice. Plant Cell 20, 2130-2145. doi: 10.1105/tpc.107.055087

Xing, Y., and Zhang, Q. (2010). Genetic and molecular bases of rice yield. Annu. Rev. Plant Biol. 61, 421-442. doi: 10.1146/annurev-arplant-042809-112209

Yang, X., Yang, Y. N., Xue, L. J., Zou, M. J., Liu, J. Y., Chen, F., et al. (2011). Rice ABI5-Like1 regulates abscisic acid and auxin responses by affecting the expression of ABRE-containing genes. Plant Physiol. 156, 1397-1409. doi: 10.1104/pp.111.173427

Zhou, S. R., Yin, L. L., and Xue, H. W. (2013). Functional genomics based understanding of rice endosperm development. Curr. Opin. Plant Biol. 16, 236-246. doi: 10.1016/j.pbi.2013.03.001

Conflict of Interest Statement: The authors declare that the research was conducted in the absence of any commercial or financial relationships that could be construed as a potential conflict of interest.

Copyright (C) 2016 Sui, Wang, Li, Zhang, Li, Xu, Xing, Ni and Xin. This is an openaccess article distributed under the terms of the Creative Commons Attribution License (CC BY). The use, distribution or reproduction in other forums is permitted, provided the original author(s) or licensor are credited and that the original publication in this journal is cited, in accordance with accepted academic practice. No use, distribution or reproduction is permitted which does not comply with these terms. 